\section{(6) OPEN ACCESS}

\title{
Carotid artery stenting without post-stenting balloon dilatation
}

\author{
Atsushi Ogata, ${ }^{1,2}$ Makoto Sonobe, ${ }^{1}$ Noriyuki Kato, ${ }^{1}$ Tomosato Yamazaki, ${ }^{1}$ \\ Hiromichi Kasuya, ${ }^{1}$ Go Ikeda, ${ }^{1}$ Shunichiro Miki, ${ }^{1}$ Toshio Matsushima ${ }^{2}$
}

${ }^{1}$ Department of Neurosurgery, National Hospital Organization, Mito Medical Center, Ibaraki, Japan

${ }^{2}$ Department of Neurosurgery, Faculty of Medicine, Saga University, Saga, Japan

\section{Correspondence to}

Dr Atsushi Ogata,

Department of Neurosurgery,

School of Medicine, Saga

University, 5-1-1 Nabeshima,

Saga-shi, Saga 849-8501,

Japan;

ogata.a24@gmail.com

Received 22 July 2013

Accepted 8 August 2013

Published Online First

7 September 2013

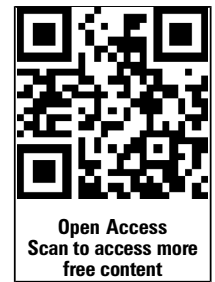

CrossMark

To cite: Ogata $A$, Sonobe $\mathrm{M}$, Kato $\mathrm{N}$, et al. J Neurolntervent Surg 2014;6:517-520.

\section{ABSTRACT}

Purpose To evaluate the clinical outcome and MRI findings after carotid artery stenting (CAS) without post-dilatation.

Methods Between May 2005 and April 2012, a total of 169 consecutive patients (61.4\% symptomatic) underwent 176 CAS procedures performed with an embolic protection device (GuardWire, $n=116$; FilterWire $E Z, n=60)$. All stents were deployed without post-dilatation. Periprocedural complications and midterm outcomes were analyzed.

Results The stroke rate was $2.3 \%$ within 30 days post-CAS (asymptomatic patients 1.5\%; symptomatic patients $2.8 \%$ ). Cerebral infarction occurred in one asymptomatic patient (1.5\%) and one symptomatic patient $(0.9 \%)$. Intracranial hemorrhage occurred in two symptomatic patients (1.9\%). Post-CAS diffusionweighted imaging (DWI) revealed a high-intensity area in 26 of 176 procedures (14.8\%). Ipsilateral stroke after 31 days occurred in two patients (1.1\%) and restenosis occurred in six $(3.4 \%)$. A post-CAS comparison of the embolic protection devices revealed no difference in stroke incidence within 30 days and in DWI highintensity area.

Conclusions Our CAS procedure without post-dilatation is feasible, safe and associated with a low incidence of stroke and restenosis.

\section{INTRODUCTION}

Carotid artery stenting (CAS) is the standard modality for patients with severe carotid artery stenosis at high risk for carotid endarterectomy. However, a major drawback of CAS is the potential risk of embolic stroke caused by the dislodgement of atheromatous plaque during the procedure. The traditional CAS procedure involves initial vascular balloon dilatation (pre-dilatation) to achieve access for other devices, followed by optional placement of an embolic protection device (EPD), positioning of a stent across the stenosis and, finally, poststenting balloon dilatation (post-dilatation) to achieve maximum vessel expansion. Emboli can arise in each procedural step, but most emboli are produced during the post-dilatation stage, which might occur if the balloon pushes the stent struts against the atheromatous plaque. Post-dilatation is therefore considered to be the riskiest part of the procedure. $^{2}$ To minimize procedural thromboembolic complications, we sometimes perform CAS without post-dilatation; the aim of this study was to evaluate the efficacy and safety of our technical strategy for CAS.

\section{METHODS \\ Patient population}

A retrospective registry between May 2005 and April 2012 was accessed to recover 171 consecutive patients with 178 carotid artery stenoses who underwent CAS with an EPD at either the National Hospital Organization Mito Medical Center (Ibaraki, Japan) or an affiliated hospital. CAS was indicated in symptomatic or asymptomatic patients by a carotid artery stenosis of $>50 \%$ or $>80 \%$, respectively, according to North American Symptomatic Carotid Endarterectomy Trial (NASCET) criteria. ${ }^{3}$ Our study included 169 patients (148 men, 21 women) with 176 carotid artery stenoses who underwent CAS without post-dilatation. The mean age of the patients was 71.9 years (range 43-88). A total of 108 lesions $(61.4 \%)$ were symptomatic and 68 (38.6\%) were asymptomatic. Our study excluded two patients who underwent CAS with post-dilatation. In addition, patients with normal-risk carotid endarterectomy underwent CAS.

\section{CAS procedure}

Patients received two of the three following antiplatelet agents: aspirin $(100 \mathrm{mg})$, clopidogrel $(75 \mathrm{mg})$ and cilostazol $(200 \mathrm{mg})$ for at least 1 week before the procedure. CAS was performed under general anesthesia in 168 procedures (95.4\%). An $8 \mathrm{~F}$ introducer sheath was inserted into the common femoral artery. Ten patients underwent CAS via the transbrachial artery. Systemic heparinization was administered following insertion of a sheath, and an activated clotting time of $300 \mathrm{~s}$ was maintained during the procedure. A guiding catheter or long sheath was advanced into the common carotid artery. Under roadmap guidance, the stenotic lesion was crossed with an EPD which was navigated distal to the stenotic lesion. All 107 CAS procedures through May 2010 were performed using the GuardWire Temporary Occlusion and Aspiration System (Medtronic, Santa Rosa, California, USA). After June 2010 we primarily performed CAS using the FilterWire EZ Embolic Protection System (Boston Scientific, Natick, Massachusetts, USA). CAS was performed using the GuardWire system for patients with soft plaque deposits, as identified by a black blood MRI indicating high-intensity and long lesions (>25 mm; figure 1). After June 2010 we performed CAS using the FilterWire EZ system for 60 lesions and the GuardWire system for nine lesions. Pre-stenting balloon dilatation was subsequently applied to the stenotic lesions after EPD placement and was usually performed using a 4.0 


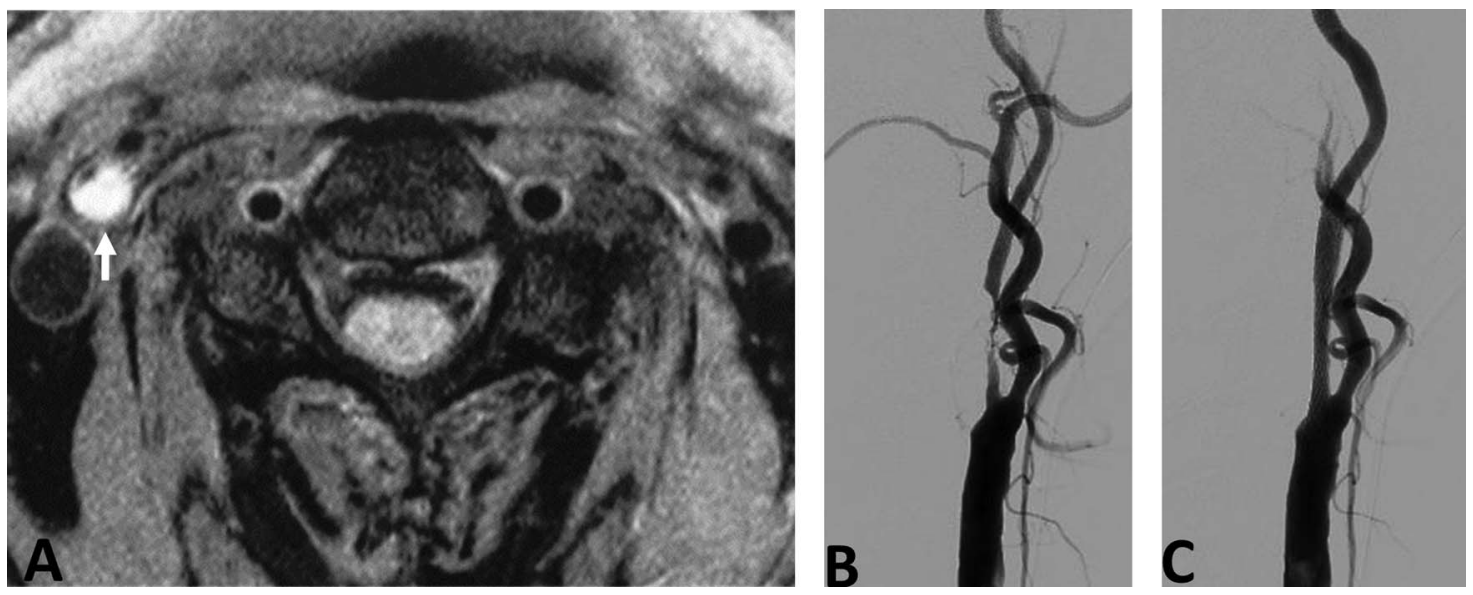

Figure 1 An octogenarian with symptomatic carotid artery stenosis who underwent carotid artery stenting using the GuardWire system. (A) Black blood T1-weighted MRI showing a high-intensity plaque lesion in the right internal carotid artery (white arrow). (B) Angiogram of the right common carotid artery showing severe stenosis of the internal carotid artery with a long lesion. (C) Post-procedural angiogram of the right common carotid artery (pre-dilatation with $4 \times 30 \mathrm{~mm}$ balloon and stent deployment with $10 \times 24 \mathrm{~mm}$ carotid Wallstent) showing improvement of the internal carotid artery stenosis.

$5.5 \mathrm{~mm} \times 30 \mathrm{~mm}$ angioplasty balloon. The most commonly used stents were Wallstents (Boston Scientific, Natick, Massachusetts, USA), which were applied in 174 lesions (98.9\%), and Precise stents (Cordis, Johnson \& Johnson, Miami, Florida, USA), which were applied in two lesions. Angiographic views of the head and neck were obtained at the onset of the procedure and after successful stent placement. Moreover, 16 patients with preoperative hemodynamic compromise or postoperative angiographic hyperemia of the lenticulostriate arteries underwent intravenous deep sedation for $24 \mathrm{~h}$ following the procedure. All the patients underwent a clinical examination (including a neurological examination) and MRI including DWI both before and $24 \mathrm{~h}$ after the procedure. Two antiplatelet agents were administered for a minimum of 3 months after surgery, after which one of the agents was discontinued. Following discharge, the patients were examined and ultrasound follow-up studies were performed at 30 days, 3 months and then once every 3 months indefinitely.

\section{Definitions}

A major adverse event was defined as any incidence of stroke, myocardial infarction or death within 30 days after CAS. Stroke was defined as a neurological deficit that persisted for $>24 \mathrm{~h}$, whereas a minor stroke was defined as a new neurological deficit that resolved completely or returned to baseline within 30 days. A transient ischemic attack (TIA) was defined as a new neurological deficit that persisted for $<24 \mathrm{~h}$ and completely resolved or returned to baseline. Restenosis was defined as $>50 \%$ stenosis. In cases with ultrasonic signs of restenosis, the severity was confirmed using repeated carotid angiograms. Angiographic stenosis of $>80 \%$ was indicated for repeated intervention.

\section{Statistical analysis}

Statistical analysis was performed to evaluate the efficacy of our CAS procedure according to EPD as well as the proportion of residual stenosis immediately after the procedure. Nominal data were analyzed using the Fisher exact test and numerical data were analyzed using the $t$ test for parametric values or the Mann-Whitney $U$ test for non-parametric values. A $p$ value $<0.05$ was considered statistically significant.

\section{RESULTS}

CAS was performed successfully for all lesions, although major adverse events occurred in four patients (2.3\%). The overall stroke rate was $2.3 \%$ within 30 days after CAS; none of the patients experienced myocardial infarction and there were no deaths. Cerebral infarction and intracranial hemorrhage occurred in two patients each (1.1\%) and TIA occurred in three patients (1.7\%). DWI obtained after CAS revealed a highintensity area in 26 of 176 procedures (14.8\%). In 68 asymptomatic patients, one minor stroke $(1.5 \%)$ occurred because of subacute instent thrombosis, one TIA (1.5\%) occurred within 30 days after CAS and DWI obtained $24 \mathrm{~h}$ after CAS revealed a high-intensity area in seven procedures (10.3\%). In 108 symptomatic patients, one minor stroke $(0.9 \%)$ occurred because of thromboembolic complications. Two intracranial hemorrhages and two TIAs (1.9\%) occurred within 30 days after CAS, and DWI obtained $24 \mathrm{~h}$ after CAS revealed a high-intensity area in $19(17.6 \%)$ procedures (table 1). Subacute in-stent thrombosis complicated with TIA developed in one of the symptomatic patients. Furthermore, among the patients with intracranial hemorrhage, one developed permanent hemiparesis.

Follow-up data beyond 1 year for all 176 lesions included two cases of symptomatic restenosis. The ipsilateral stroke rate

Table 1 Procedural outcomes

\begin{tabular}{|c|c|c|c|}
\hline & $\begin{array}{l}\text { Total } \\
(n=176)\end{array}$ & $\begin{array}{l}\text { Asymptomatic } \\
(n=68)\end{array}$ & $\begin{array}{l}\text { Symptomatic } \\
(n=108)\end{array}$ \\
\hline Any stroke & $4(2.3 \%)$ & $1(1.5 \%)$ & $3(2.8 \%)$ \\
\hline Ischemic stroke & $2(1.1 \%)$ & $1(1.5 \%)$ & $1(0.9 \%)$ \\
\hline Hemorrhagic stroke & $2(1.1 \%)$ & 0 & $2(1.9 \%)$ \\
\hline $\begin{array}{l}\text { Myocardial } \\
\text { infarction }\end{array}$ & 0 & 0 & 0 \\
\hline Death & 0 & 0 & 0 \\
\hline $\begin{array}{l}\text { Major adverse } \\
\text { event* }^{*}\end{array}$ & $4(2.3 \%)$ & $1(1.5 \%)$ & $3(2.8 \%)$ \\
\hline TIA & $3(1.7 \%)$ & $1(1.5 \%)$ & $2(1.9 \%)$ \\
\hline DWI high intensity & $26(14.8 \%)$ & $7(10.3 \%)$ & $19(17.6 \%)$ \\
\hline
\end{tabular}

* Major adverse event defined as any stroke/myocardial infarction/death. DWI, diffusion-weighted imaging; TIA, transient ischemic attack. 
was $1.1 \%$ (symptomatic $1.9 \%$; asymptomatic $0 \%$ ) after 31 days. Two symptomatic patients with restenosis had minor strokes and were treated conservatively. Moreover, four asymptomatic restenosis cases were diagnosed during follow-up ultrasound examinations; subsequently, three of these patients underwent angioplasty and the overall restenosis rate was 3.4\%.

The mean stenosis diameter according to the NASCET criteria $^{3}$ was reduced from $75.0 \pm 11.8 \%$ to $17.3 \pm 11.2 \%$. The immediate angiographic outcomes after CAS were as follows: residual stenosis $\leq 10 \%(n=54,30.7 \%)$; residual stenosis $>10 \%$ and $\leq 20 \%(\mathrm{n}=52,29.5 \%)$; residual stenosis $>20 \%$ and $\leq 30 \%$ $(\mathrm{n}=43,24.4 \%)$; residual stenosis $>30 \%$ and $\leq 40 \% \quad(\mathrm{n}=22$, $12.5 \%)$; and residual stenosis $>40 \%(n=5,2.8 \%)$. Restenosis or subacute in-stent thrombosis after CAS was observed in eight patients. The mean stenosis rate immediately after CAS was $32.1 \%$ in this group, compared with $16.9 \%$ in the group without restenosis or subacute in-stent thrombosis. Thus, the mean stenosis rate immediately after CAS was significantly higher in the group with restenosis or subacute in-stent thrombosis $(p=0.0004)$. Five of 27 patients $(18.5 \%)$ with residual stenosis immediately after CAS $>30 \%$ suffered restenosis or in-stent thrombosis and three of 149 patients (2.0\%) without residual stenosis immediately after CAS $>30 \%$ suffered restenosis or in-stent thrombosis. The rate of restenosis or in-stent thrombosis was significantly higher in the group with residual stenosis immediately after CAS $>30 \%$ (table 2 ).

A comparison of EPD (table 3 ) revealed no difference in the incidence of stroke within 30 days after CAS and high intensity areas on DWI obtained $24 \mathrm{~h}$ after CAS.

\section{DISCUSSION}

Strokes arising from carotid stenosis are most often due to atheroembolisms. ${ }^{4-6}$ During carotid endarterectomy the plaque is completely removed; however, with carotid stenting, the plaque remains contained between the stent and the vessel wall. Stroke occurring after CAS is probably caused by the release of fractured plaque deposits through the struts of the stent. In the Carotid Revascularization Endarterectomy versus Stenting Trial, ${ }^{7}$ the periprocedural stroke rate was significantly higher in the stenting group than in the endarterectomy group $(4.1 \%$ vs $2.3 \%, \mathrm{p}=0.01)$.

Transcranial Doppler studies have demonstrated the generation of emboli with each passage across a stenosis with a guidewire, EPD, balloon or stent, ${ }^{8}{ }^{9}$ with the highest potential for embolization occurring during post-dilatation when the balloon crushes friable plaque against the metal stent struts. ${ }^{89}$ Although the clinical significance of microemboli is unclear, Ackerstaff et $a l^{10}$ demonstrated in a study of 550 patients that multiple microemboli ( $>5$ showers) at post-dilatation were independently associated with cerebral deficits. The traditional CAS technique includes initial balloon pre-dilatation during which the

Table 2 Comparison of the procedural outcomes according to the residual stenosis immediately after carotid artery stenting (CAS)

\begin{tabular}{llll}
\hline & \multicolumn{2}{l}{$\begin{array}{l}\text { Residual stenosis rate } \\
\text { immediately after CAS }\end{array}$} & \\
\cline { 2 - 3 } & $>\mathbf{3 0 \% ( n = 2 7 )} \quad \leq 30 \%(\mathrm{n}=149)$ & p Value \\
\hline Restenosis & $3(11.1 \%)$ & $3(2.0 \%)$ & 0.047 \\
In-stent thrombosis & $2(7.4 \%)$ & 0 & 0.023 \\
Restenosis or in-stent thrombosis & $5(18.5 \%)$ & $3(2.0 \%)$ & 0.002 \\
\hline
\end{tabular}

Table 3 Comparison of the procedural outcomes between patients treated with the GuardWire (GW) and FilterWire EZ (FW) systems

\begin{tabular}{lcccc}
\hline & Total $(\mathbf{n}=\mathbf{1 7 6 )}$ & GW $(\mathbf{n}=116)$ & FW (n=60) & p Value \\
\hline Any stroke & $4(2.3 \%)$ & $4(3.4 \%)$ & 0 & 0.30 \\
Ischemic stroke & $2(1.1 \%)$ & $2(1.7 \%)$ & 0 & 0.55 \\
Hemorrhagic stroke & $2(1.1 \%)$ & $2(1.7 \%)$ & 0 & 0.55 \\
DWI high intensity & $26(14.8 \%)$ & $16(13.8 \%)$ & $10(16.7 \%)$ & 0.82 \\
\hline \multicolumn{7}{l}{ DWI, diffusion-weighted imaging. }
\end{tabular}

EPD or stent is accessible distal to the stenosis, subsequent optional placement of the EPD followed by deployment of a stent covering the stenosis, and finally post-dilatation to achieve maximum vessel expansion after stent deployment. We performed CAS without post-dilatation to minimize plaque disruption and the incidence of periprocedural stroke. The results of this study revealed a relatively low incidence of complications within 30 days after the procedure $(2.3 \%$ overall stroke, death or myocardial infarction).

Symptomatic patients are known to have emboligenic plaque. ${ }^{11}$ In the Carotid Revascularization Endarterectomy Versus Stenting Trial, the rate of any post-procedural stroke within 30 days was $5.5 \%$ in symptomatic patients treated with CAS and $3.2 \%$ in symptomatic patients treated with carotid endarterectomy. $^{7}$ In this study, the rate of any post-procedural stroke within 30 days was $1.5 \%$ in asymptomatic patients and $2.8 \%$ in symptomatic patients. In symptomatic patients, the incidence of periprocedural stroke was relatively low in this study because the omission of post-dilatation might have minimized plaque disruption and reduced thromboembolic complications.

Most embolic complications occur after the procedure and are probably caused by late emboli through the struts of the stent, as described above. ${ }^{11}$ A closed cell stent has smaller struts than an open cell stent. ${ }^{12}$ Bosiers et al ${ }^{11}$ reported that the rate of post-procedural events was higher when using the open cell stent than when using the closed cell stent. These differences were highly pronounced among symptomatic patients. ${ }^{11}$ Wallstents, the most commonly used stents in this study, were applied in 174 lesions (98.9\%). In addition to the omission of post-dilatation, the use of a Wallstent might also reduce thromboembolic complications.

The closed cell stent has a lower radial force than an open cell stent, ${ }^{12}$ and poor stent expansion immediately after the procedure was associated with a higher risk of restenosis. ${ }^{13}$ Furthermore, omission of post-dilatation and the use of a closed cell stent might cause restenosis. A systematic review by Gröschel et $a l^{14}$ reported a restenosis rate with conventional CAS of $4-6 \%$ at 1 year; the rate of restenosis with our CAS protocol (3.4\%) was therefore lower than that previously reported. In our procedure, the goal of pre-dilatation was to enlarge the stenotic lumen suboptimally with only the balloon. Therefore, pre-dilatation alone without post-dilatation can achieve a sufficient luminal opening to prevent restenosis. On the other hand, arterial injury with both balloons and stents can initiate an inflammatory response and activate a proliferative repair process, the end result of which can lead to luminal narrowing and in-stent restenosis. ${ }^{15-19}$ In fact, omission of postdilatation and the use of a closed cell stent might be beneficial to minimize such restenosis incidents. On the other hand, the rate of restenosis or in-stent thrombosis was significantly higher in the patient group with $>30 \%$ residual stenosis immediately 
after CAS in the present study. Post-dilatation might therefore be added to avoid restenosis and in-stent thrombosis in patients with $>30 \%$ residual stenosis. Nevertheless, additional postdilatation might induce thromboembolic complications, particularly in symptomatic patients with unstable risky plaque deposits. In cases with $>30 \%$ residual stenosis immediately after CAS, we should consider whether or not to add post-dilatation to the procedure for symptomatic patients and decide how much postdilatation to add.

In a previous study to evaluate microembolic signals detected by transcranial Doppler during CAS, the amount of microembolic signals was significantly higher using the FilterWire system than with the GuardWire system. ${ }^{20}$ The distal occlusion device is thought to be more effective than the filter in reducing distal embolization. ${ }^{20}$ However, balloon occlusion (whether proximal or distal) is associated with cerebral intolerance in $5-10 \%$ of cases. $^{2122}$ On the other hand, the main advantage of filters is the maintenance of blood flow to the brain throughout the procedure. A comparison of EPDs revealed no difference in the incidence of stroke within 30 days after CAS and the highintensity area on DWI obtained $24 \mathrm{~h}$ after CAS in the present study. CAS without post-dilatation can take advantage of filter protection because of the reduction in distal embolisms.

We acknowledge several limitations to our study. First, the study was observational and not case-controlled. Second, we could not observe any advantage of omission of post-dilatation using the open cell stent, although closed cell stents were used in 174 lesions (98.9\%) while open cell stents were used in only two lesions. Lastly, this analysis could be improved by a longer radiological and clinical follow-up period to further evaluate the clinical significance.

\section{CONCLUSIONS}

Carotid stenting without post-dilatation might achieve minimal plaque disruption and reduction of thromboembolic complications. Our CAS procedure is effective, particularly in symptomatic patients. Although it might be possible to employ new types of stents and EPDs in the future, concepts to minimize plaque disruption are important because plaque deposits remain contained in the vessel wall in carotid stenting procedures.

Correction notice This article has been corrected since it was published Online First. The asymptomatic patients percentage has been amended to $1.5 \%$.

Contributors All authors met the criteria for authorship according to BMJ guidelines.

Competing interests None.

Patient consent Obtained.

Provenance and peer review Not commissioned; externally peer reviewed.

Data sharing statement A synopsis of our original dataset is presented in the current paper. However, additional data including explanatory material and complete datasets are available to fellow researchers on request.

Open Access This is an Open Access article distributed in accordance with the Creative Commons Attribution Non Commercial (CC BY-NC 3.0) license, which permits others to distribute, remix, adapt, build upon this work non-commercially, and license their derivative works on different terms, provided the original work is properly cited and the use is non-commercial. See: http://creativecommons.org/ licenses/by-nc/3.0/

\section{REFERENCES}

1 Vitek JJ, Roubin GS, al-Mubarak N, et al. Carotid artery stenting: Technical considerations. AJNR Am J Neuroradiol 2000:21:1736-43.

2 Martin JB, Pache JC, Treggiari-Venzi M, et al. Role of the distal balloon protection technique in the prevention of cerebral embolic events during carotid stent placement. Stroke 2001;32:479-84.

3 North American Symptomatic Carotid Endarterectomy Trial Collaborators. The beneficial effects of carotid endarterectomy in symptomatic patients with high-grade carotid stenosis. N Engl J Med 1991;325:445-53.

4 Fisher CM. Occlusion of the internal carotid artery. AMA Arch Neurol Psychiatry 1951;65:346-77

5 Fisher CM. Transient monocular blindness associated with hemiplegia. AMA Arch Ophthalmol 1952;47:167-203.

6 Martin MJ, Whisnant JP, Sayre GP. Occlusive vascular disease in extracranial cerebral circulation. Arch Neurol 1960;3:530-8.

7 Brott TG, Hobson RW II, Howard G, et al. Stenting versus endarterectomy for the treatment of carotid artery stenosis. N Engl J Med 2010;363:11-23.

8 Manninen HI, Räsänen HT, Vanninen RL, et al. Stent placement versus percutaneous transluminal angioplasty in cadavers in situ: distal embolization and findings at intravascular US, MR images and histopathologic analysis. Radiology 1992;212:483-92.

9 Vos JA, van den Berg JC, Ernst SM, et al. Carotid angioplasty and stent placement: comparison of transcranial Doppler US date and clinical outcome with and without filtering cerebral protection devices in 509 patients. Radiology 2005;234:493-9.

10 Ackerstaff RG, Suttorp MJ, van den Berg JC. Prediction of early cerebral outcome by transcranial Doppler monitoring in carotid bifurcation angioplasty and stenting. J Vasc Surg 2005;41:618-24

11 Bosiers $M$, de Donato G, Deloose K, et al. Does free cell area influence the outcome in carotid artery stenting? Eur J Vasc Endovasc Surg 2007;33:135-41.

12 Müller-Hülsbeck S, Schäfer PJ, Charalambous N, et al. Comparison of carotid stents: an in-vitro experiment focusing on stent design. J Endovasc Ther 2009;16:168-77.

13 Clark DJ, Lessio S, O'Donoghue $\mathrm{M}$, et al. Mechanisms and predictors of carotid artery stent restenosis. A serial intravascular ultrasound study. J Am Coll Cardiol 2006:47:2390-96.

14 Gröschel K, Riecker A, Schulz JB, et al. Systematic review of early recurrent stenosis after carotid angioplasty and stenting. Stroke 2005;36:367-73.

15 Barth KH, Virmani R, Froelich J, et al. Paired comparison of vascular wall reactions to Palmatz stents, Strecker tantalum stents and Wallstents in canine iliac and femoral arteries. Circulation 1996:93:2161-9.

16 Schillinger $M$, Exner $M$, Mlekusch $W$, et al. Acute-phase response after stent implantation in the carotid artery: association with 6 month in-stent restenosis. Radiology 2003;227:516-21.

17 Farb A, Sangiorgi G, Carter A, et al. Pathology of acute and chronic coronary stenting in humans. Circulation 1999;99:44-52.

18 Schillinger M, Exner M, Mlekusch W, et al. Inflammatory response to stent implantation: differences in femoropopliteal, iliac and carotid arteries. Radiology 2002;224:529-35.

19 Farb A, Weber DK, Kolodgie FD, et al. Morphologic predictors of restenosis after coronary stenting in humans. Circulation 2002;105:2974-80.

20 Rubartelli P, Brusa G, Arrigo A, et al. Transcranial Doppler monitoring during stenting of carotid bifurcation: evaluation of two different distal protection devices in preventing embolization. J Endovasc Ther 2006;13:436-42.

21 Whitlow PL, Lylyk P, Londero $\mathrm{H}$, et al. Carotid artery stenting protected with an emboli containment system. Stroke 2002;33:1308-14.

22 Powell RJ, Alessi C, Nolan B, et al. Comparison of embolization protection device-specific technical difficulties during carotid artery stenting. I Vasc Surg 2006;44:56-61. 